\title{
Effects of Transporting a Baby with Varied Baby Carriers on the Posture of Mother during Gait
}

\author{
'Sangmyung University, Seoul, Korea \\ ${ }^{2}$ Kookmin University, Seoul, Korea \\ ${ }^{3} \mathrm{~K} 2$ Korea Co., Seoul, Korea \\ ${ }^{4}$ Konyang University, Nonsan, Korea
}

Yeon Joo Yu', Ki Kwang Lee², Jung Ho Lee ${ }^{3}$, Suk Bum Kim*

Received: May 11, 2018

Accepted: July 18, 2018

Published online: July 31, 2018

Keywords:

Baby carrier

Body posture

Gait

Ground reaction force
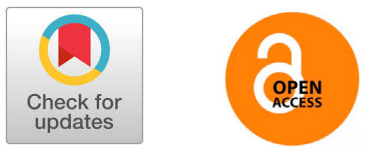

\begin{abstract}
OBJECTIVES The purpose of the study was to investigate weight distribution, posture alignment, and gait parameters while a mother was transporting a baby with varied baby carriers during gait.

METHODS Five mothers transported their babies with three different baby carriers(baby carrier, hipseat carrier, \& hipseat) and carried babies with their arms. Ten cameras, marker sets, and forceplatforms were used to get the kinematic, force, and gait parameters.

RESULTS The hipseat showed that the range of motion in the hip joint was small, the step length and stride length was short, and the gait velocity was slow. Mothers carried their babies with arms showed that lower in the trunk flexion angle, larger in the stride length, and faster in the gait velocity were than any other baby carriers.

CONCLUSIONS The baby carrier is important for infant's growth and care, but there is lack of product appropriateness, use, and scientific basis. Therefore, further study is needed to investigate varied performance with transporting a baby with baby carriers.
\end{abstract}

(c) The Asian Society of Kinesiology and the Korean Academy of Kinesiology
서론

임신한 여성의 인체는 태아의 성장에 따라 몸무게가 변 화되고, 신체 정렬의 변화가 나타난다. 몸무게의 점진적 인 증가는 인체의 무게중심을 배 앞쪽에 위치시키고, 경추 와 요추만곡을 증가시키며, 몸통의 신전을 증가시킨다[1, 2]. 이러한 자세 정렬의 변화는 일상생활 속 보행, 서기 자 세, 의자에서 일어서기 등의 동작을 행할 때 인체가 평형 을 유지하기 위해 새로운 체중 분배를 하는 것으로 밝혀졌 다[3]. 인체 자세 정렬의 변화는 요통 발생의 원인이 되기

*Correspondence: Suk Bum Kim, Konyang University, 121, Daehak-ro, Nonsan-si, Chungcheongnam-do, 32992 Korea.

E-mail: bum3340@Konyang.ac.kr
도 하는데, Wang et al. [4]은 임신기간 동안 가장 많이 발생 하는 통증을 요통 $(50.9 \%)$ 으로 보고하였다. 아이를 출산 한 임산부의 $72 \%$ 가 요추와 골반 부위의 통증을 경험하였고, 아이 출산 후 약 3 년 동안 하요부와 골반 부위의 계속적인 통증을 호소하였다 $[5,6]$.

여성이 출산 후 아기를 돌보면서 행하는 많은 동작들 중 아기 안기와 업기 동작은 자세 정렬에 영향을 주며, 손 목, 목, 어깨, 그리고 허리 등에 근골격계 질환을 일으킨다 [7]. 아기를 재우고, 달래고, 산책시키기 위해 안거나 업기 도 하지만, 많은 수의 여성들이 육아와 동시에 가사를 병 행하기에 아기를 안거나 업고 두 과제(청소하기, 장보기, 설거지 등)를 동시에 행하기도 한다. 육아 용품 중 아기 캐 리어는 엄마가 아기를 안거나 업고도 손을 자유롭게 움직 
일 수 있어 아기 돌봄 이외의 다른 활동을 할 수 있으며, 아 기의 체중부하를 분산시켜 오랜 시간 동안 아기를 안거나 업는 것이 가능하다. 또한 엄마 신체와 밀착할 수 있어 애 착형성과 심리적 안정에도 도움을 주며, 팔로만 아기를 안았을 때 보다 생리학적 에너지 소모 또한 낮은 것으로 보고되었다[8]. 2018년 현재 아기 캐리어 시장은 전통적 인 우리의 처네(포대기)와는 다른 형태인 아기띠, 힙시트, 그리고 힙시트 캐리어로 나누어지며, 국내에선 소수의 제 품들이 제조되고 국외로부터 다양한 제품들이 수입되고 있다. 인터넷 시장에서 많이 유통되는 아기 캐리어의 제 조사와 공식 수입 업체의 홈페이지를 살펴보면, 스르랜 드는 아기 캐리어의 사용 가능한 적정 개월 수와 몸무게 를 제시하지 않았고, 프 브랜드는 적정개월 수와 몸무게 를 아기띠 (신 생아 $\sim 36$ 개월, $3.5 \mathrm{~kg} \sim 5 \mathrm{~kg}$ ), 힙시트 캐리어( 신생아 $\sim 36$ 개월, $3.5 \mathrm{~kg} \sim 20 \mathrm{~kg}$ )로 제시하였고, 으브랜드 는 힙시트를 사용하기 위한 적정 개월 수는 3 36개월, 적 정 몸무게를 $3.5 \mathrm{~kg} \sim 20 \mathrm{~kg}$ 로 제시하였다. 주로 소재(패브 릭)의 무게와 패턴, 디자인만을 소개하였고, 아기 몸무게 로 인한 부하분배나엄마의 자세 정렬과 관련된 인체공학 적인 정보는 찾기 힘들다.

아기 캐리어가 상용화 된지 오래되었고, 아기를 키우 는 엄마들이 짧게는 12 개월 길게는 약 36 개월 이상 아기 캐리어를 사용하지만 그에 따른 연구는 미흡하다. 아기 캐리어와 관련된 선행 연구를 살펴보면, 첫째, 아기띠 착 용 시 자세 정렬의 변화를 분석한 연구로 Kim \& Yun [9] 은 아기띠를 앞과 뒤로 착용한 후 바로 선 자세와 트레이 드밀 보행 시 목, 어깨, 몸통, 그리고 고관절의 변위와 각 도를 비교하였다. 둘째, 아기띠 착용 시 근육의 활동과 족 저압력의 변화를 분석한 연구들로 Yuk et al. [10]은 아기 띠
와 슬링을 비교하였고, Lee et al. [7]은 처네의 착용 위치에 따른 비교를 하였고, Chang et al.[11]은 아기띠 착용 시 팔 의 보조 유무가 목, 허리, 그리고 다리의 근육활동에 어떤 영향을 주는지 연구하였다. Lee et al. [7]의 연구를 제외하 고는 연구에 참여한 피험자들이 영아를 양육하는 여성이 아니었다[7].

따라서 실제 영아를 양육하는 엄마를 피험자로 하여 아기 캐리어 착용 후 보행을 수행하게 한다면, 보행 패턴 과 자세 정렬에 대한 새로운 자료가 도출될 것이다. 또한 대부분의 연구에서 아기 캐리어 안에 아기 대신 인형을 사용하였는데, 아기와 인형의 무게가 동일할지라도 아기 를 안고 걸을 때 느끼는 심리상태(안전, 보호)는 보행 변수 에 영향을 줄 것으로 생각된다.

본 연구는 다양한 아기 캐리어 착용 후 보행 시 체중분 배, 자세 정렬과 보행 변수의 변화를 분석하는 것이다. 구 체적으로 엄마 피험자는 세 종류의 아기 캐리어(아기띠, 힙시트캐리어, \& 힙시트)를 사용하여 자신의 아이를 안 고 보행하는 과제들을 수행할 것이고, 더불어 아기 캐리 어를 사용하지 않은 채 아기를 가슴에 안고 걷는 일반 보 행 과제를 수행할 것이다.

\section{연구 방법}

\section{연구대상}

본 연구에는 엄마 5 명과 그들의 아기 5 명이 참여하였 고, 엄마 피험자들은 근골격계 질환 및 수술 경험이 없는 자들이다<Table $1>$.

\section{측정항목 및 방법}

\begin{tabular}{|c|c|c|c|c|c|c|}
\hline $\begin{array}{c}\text { Mom } \\
\text { Number }\end{array}$ & $\begin{array}{l}\text { Age } \\
\text { (yrs) }\end{array}$ & $\begin{array}{l}\text { Height } \\
(\mathrm{cm})\end{array}$ & $\begin{array}{c}\text { Weight } \\
(\mathrm{kg})\end{array}$ & $\begin{array}{c}\text { Baby } \\
\text { Number }\end{array}$ & $\begin{array}{c}\text { Age } \\
\text { (months) }\end{array}$ & $\begin{array}{c}\text { Weight } \\
\text { (kg) }\end{array}$ \\
\hline 1 & 42 & 158 & 53 & 1 & 18 & 11 \\
\hline 2 & 44 & 156 & 46 & 2 & 18 & 11 \\
\hline 3 & 34 & 158.3 & 60 & 3 & 18 & 11 \\
\hline 4 & 32 & 168 & 63 & 4 & 12 & 11 \\
\hline \multirow[t]{2}{*}{5} & 31 & 165 & 70 & 5 & 17 & 10.5 \\
\hline & $36.6 \pm 5.98$ & $161.06 \pm 5.15$ & $58.4 \pm 9.23$ & & $16.6 \pm 2.60$ & $10.9 \pm 0.22$ \\
\hline
\end{tabular}




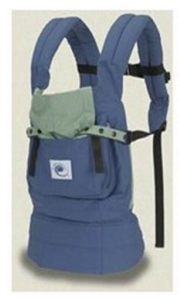

A. Baby carrier

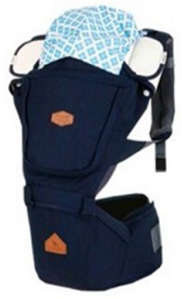

B. Hipseat carrier

Figure 1. Three different baby carriers

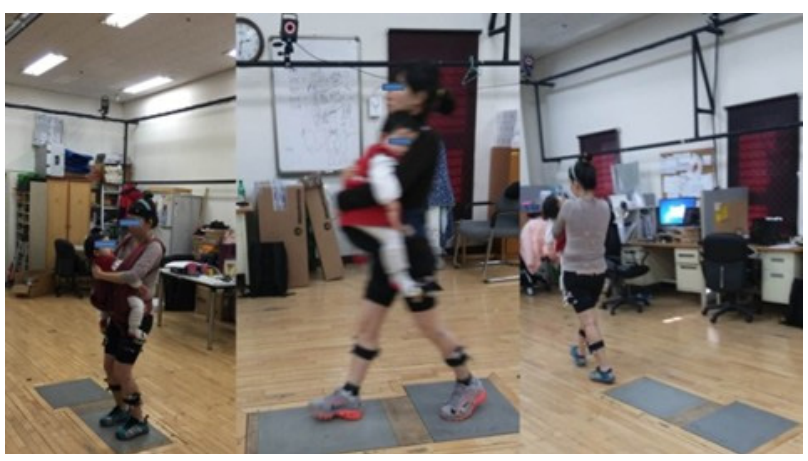

Figure 2. Transporting a baby with varied baby carriers

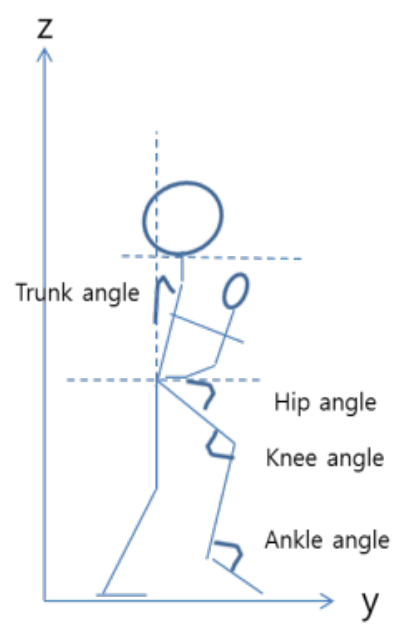

Figure 3. Joint angle definition
실험도구 실험은 $8 \mathrm{~m}$ 의 보행 주로를 중심으로 이루어 지며, 10 대의 3 차원 동작 분석 카메라((MX-T40, Vicon Inc, $\mathrm{UK}), 200 \mathrm{~Hz}$ )를 설치하여 피험자들의 보행 동작이 분석되 었다. 10 대의 적외선 카메라는 피험자의 신체에 부착된 마커를 감지하고 이 정보는 다시 카메라로 보내져 동작 분석 통합 시스템(Vicon MX Giganet)을 통해 디지털 신 호로 전환된다. 두 대의 지면반력기(AMTI MSA-6, USA)
는 보행 주로의 약 $4 \mathrm{~m}$ 지점에 위치하며, 보행주기의 첫 번째 발과 두 번째 발의 지면반력이 측정되었으며, 자료 는 $1000 \mathrm{~Hz}$ 로 수집되었다. 실험에 사용된 아기 캐리어는 Figure 1과 같다.

실험 절차 및 방법 연구자는 피험자에게 실험의 목적, 방법, 실험 과제를 자세히 설명하였고, 피험자들은 실험 동의서에 서명을 하였다. 연구자는 엄마 피험자와 아기 의 신체적 특성, 아기 캐리어의 사용 용도와 빈도를 조사 하였다.

엄마 피험자는 실험의 편의를 위해 반팔과 반바지를 착 용하고 평소 피험자의 걸음걸이를 구현하기 위해 본인의 운동화를 신고 실험에 참여하였다. 운동학적 자료를 얻기 위해 인체의 주요 관절 및 분절(머리(Forehead, R/L head, Chin), 팔(R/L upper arm, R/L medial lbow, $\mathrm{R} / \mathrm{L}$ later lbow, $\mathrm{R} / \mathrm{L}$ medial wrist, $\mathrm{R} / \mathrm{L}$ later wrist, hand), 몸통(R/L Shoulder, Trunk), 골반(sacrum, R/L ASIS, R/L LIAC, R/L GT), 다리 (R/L thigh $\mathrm{R} / \mathrm{L}$ medial knee, $\mathrm{R} / \mathrm{L}$ later knee, $\mathrm{R} / \mathrm{L}$ shank, $\mathrm{R} / \mathrm{L}$ medial ankle, R/L later ankle, 발(R/L META5, R/L Styloid, R/L cunniform))과 운동화 겉면의 발뒤꿈치 중심부와 첫 번째 중족골 경부에 마커를 부착하였다.

엄마 피험자와 아기가 세 종류의 아기 캐리어와 실험 실 환경에 익숙해지도록 보행을 연습하였다. 연구자는 엄 마 피험자들에게 평소의 보행 속도로 두 대의 지면반력 기 위를 자연스럽게 밟고 지나가도록 지시하였고, 아기 의 안전을 위해 아기 캐리어의 안전 스트랩을 단단히 고 정시켰으며, 아기와 엄마 피험자가 안정감을 느낄 때 보 행을 수행하도록 하였다. 엄마 피험자들은 세 종류의 아 기 캐리어(A: 아기띠, B: 힙시트 캐리어, \& C: 힙시트)에 자 신의 아기를 안고 각각 5 회의 보행 과제를 수행하였으며, 아기 캐리어 없이 아기를 가슴에 안고 걷는 일반 보행 과 제(Normal)도 5 회 수행하였다. 아기 캐리어의 착용 순서 는 무작위로 진행되었다(Figure 2).

\section{자료 산출 및 분석}

운동학 변인 영상분석장비를 사용하여 얻은 자료는 Nexus 1.4 프로그램으로 계산된다. 분석구간은 첫 번째 지 면반력기에 내딛은 왼발의 첫 번째 뒤꿈치 착지(first heelstrike)로부터 동일한 발의 두 번째 뒤꿈치 착지까지이다 (second heel-strike). 분석구간에서 몸통, 엉덩이, 무릎과 발 목관절의 각도를 구하였고(Figure3), 보행 변수인 지지기, 
Table 2. Hip, knee, and ankle joint angels in sagittal plane (Mean \pm SD)

\begin{tabular}{|c|c|c|c|c|c|}
\hline Sagittal plane angle(deg) & & Normal & $\begin{array}{l}\text { Baby } \\
\text { carrier }\end{array}$ & Hipseat & Hipseat \\
\hline \multirow{3}{*}{$\operatorname{Max}$} & Right & $28.64 \pm 4.35$ & $32.04 \pm 14.38$ & $30.51 \pm 9.90$ & $28.74 \pm 8.90$ \\
\hline & Left & $24.49 \pm 5.93$ & $27.52 \pm 13.99$ & $27.19 \pm 5.06$ & $26.84 \pm 6.55$ \\
\hline & & & & & \\
\hline \multirow{2}{*}{ Min } & Right & $-14.09 \pm 5.1$ & $-10.27 \pm 16.96$ & $-12.36 \pm 10.70$ & $-13.68 \pm 11.99$ \\
\hline & Left & $-16.91 \pm 7.0$ & $-13.15 \pm 16.09$ & $-12.48 \pm 8.84$ & $-12.05 \pm 9.57$ \\
\hline \multirow[b]{4}{*}{ Knee } & Right & $64.01 \pm 2.54$ & $62.90 \pm 7.93$ & $61.66 \pm 4.81$ & $60.5 \pm 4.85$ \\
\hline & & & & & \\
\hline & Left & $61.88 \pm 5.24$ & $59.05 \pm 7.37$ & $62.24 \pm 5.66$ & $61.50 \pm 3.41$ \\
\hline & & & & & \\
\hline \multirow[b]{2}{*}{ Min } & Right & $-1.62 \pm 4.55$ & $-4.54 \pm 8.96$ & $-4.35 \pm 9.45$ & $-5.08 \pm 8.03$ \\
\hline & Left & $-6.38 \pm 5.37$ & $-9.33 \pm 8.66$ & $-8.74 \pm 7.98$ & $-6.93 \pm 5.45$ \\
\hline \multirow{7}{*}{ Ankle } & Right & $-7.96 \pm 3.22$ & $-6.92 \pm 4.09$ & $-8.08 \pm 3.38$ & $-6.80 \pm 5.14$ \\
\hline & & & & & \\
\hline & Left & $-7.01 \pm 3.25$ & $-4.60 \pm 1.68$ & $-5.68 \pm 5.37$ & $-4.72 \pm 1.06$ \\
\hline & & & & & \\
\hline & Right & $-42.98 \pm 2.8$ & $-39.4 \pm 2.56$ & $-42.24 \pm 2.65$ & $-38.96 \pm 5.01$ \\
\hline & & & & & \\
\hline & Left & $-46.86 \pm 5.0$ & $-43.19 \pm 3.81$ & $-45.7 \pm 5.85$ & $-42.56 \pm 3.51$ \\
\hline
\end{tabular}

보폭, 활보장과 보행 속도를 구하였다.

보폭(step length)은 양발 지지상태에서 앞에 위치한 발 의 뒤꿈치의 수평 위치로부터 뒤에 위치한 발의 뒤꿈치까 지의 수평 위치의 차이로 계산된다. 활보장(stride length) 은 동일한 발이 연속적으로 이동한 거리로써 첫 번째 지 면반력기에 내딛은 발의 뒤꿈치의 수평 위치로부터 동일 한 발의 두 번째 뒤꿈치의 착지 시 수평 위치의 차이로 계 산된다. 보행 속도(gait velocity)는 지면반력기가 위치한 분석 구간을 중심으로 약 $2 \mathrm{~m}$ 구간에서 피험자의 상후장 골극의 수평 움직임으로 계산된다.

지면반력 변인 피험자가 첫 번째 지면반력기에 먼저 내 딛는 왼발과 두 번째 지면반력기에 내딛는 오른발의 수 직지면반력(Vertical Ground Reaction Force)이 분석되었으 며, 지면반력 자료는 Visual 3D(C-Motion Inc., USA) 프로 그램으로 분석되었다.

통계처리 본 연구의 목적은 다양한 아기 캐리어 착용 후 보행 시 체중분배, 자세 정렬과 보행 변수의 변화를 분 석하는 것이다. 그러나 피험자의 수가 작기에 통계는 기
술 분석만 수행되었다.

\section{결과}

\section{운동학 결과}

시상면에서의 엉덩이관절, 무릎관절, 발목관절의 각도 아 기 캐리어를 사용하지 않고 아기를 안고 걸을 때 오른쪽 엉덩이관절은 $28.64 \pm 4.35^{\circ}$ 로 다양한 아기 캐리어를 사 용해서 걸을 때 보다 가장 작게 나타났고, 무릎의 각도 는 $64.01 \pm 2.54^{\circ}$ 로 세가지 아기 캐리어를 사용했을 때 보 다 크게 나타났다. 아기 캐리어를 사용하지 않고 아기 를 안고 걸을 때 발목의 최대각도와 최소각도를 뺀 값 은 약 $35^{\circ}$ 로 가장 크게 나타났다(Table 2). 아기 캐리어 중 힙시트를 사용하여 아기를 안고 걸었을 때 엉덩이관 절의 굴곡 $\left(28.74 \pm 8.90^{\circ}\right)$ 이 가장 작게 나타났으며, 신전 $\left(-13.68 \pm 11.99^{\circ}\right)$ 또한 작게 나타났다. 세 종류의 아기 캐리 어 중 아기띠 착용 후 보행 시 무릎관절의 활동범위가 가 장 컸으며, 힙시트 캐리어 착용 시 발목의 움직임이 가장 활발하게 나타났다. 
Table 3. Trunk angles in sagittal plane (Mean \pm SD)

\begin{tabular}{ccccc}
\hline Trunk(deg) & Normal & $\begin{array}{c}\text { Baby } \\
\text { carrier }\end{array}$ & $\begin{array}{c}\text { Hipseat } \\
\text { carrier }\end{array}$ & Hipseat \\
\hline Max & $13.04 \pm 5.72$ & $19.59 \pm 4.63$ & $19.23 \pm 5.44$ & $20.47 \pm 5.53$ \\
Min & $4.08 \pm 3.96$ & $12.47 \pm 4.27$ & $10.54 \pm 4.35$ & $11.72 \pm 5.36$ \\
\hline
\end{tabular}

시상면에서 몸통관절의 각도 몸통관절의 각도는 정적 인 서기 자세(Quiet Standing)에서의 몸통 각도와 보행 시 몸통의 진행방향 $(\mathrm{y})$ 으로 기울진 각도의 차이이다. 아기 캐리어 사용 시 몸통의 최대각도는 $19^{\circ}$ 이상으로 나타났 고, 아기를 가슴에 안고 걷는 동작 시 몸통의 최대각도는 $13^{\circ}$ 로 나타났다(Table 3).

보행변인 세 종류의 아기 캐리어를 사용하여 걷는 경 우와 아기를 캐리어 없이 안고 걸었을 때 지지구간의 평 균값은 거의 차이가 없었다(Table 4). 보폭은 힙시트를 사 용하여 아기를 안고 걸었을 때 $(64.10 \pm 3.83 \mathrm{~cm})$ 다른 조건 들에서 보다 작게 나타났다. 활보장은 아기를 가슴에 안 고 걸을 때 $(132.42 \pm 5.44 \mathrm{~cm})$ 가장 크게 나타났으며, 아기 캐리어 사용 조건의 경우 힙시트 사용 시 $(127.03 \pm 7.77 \mathrm{~cm})$ 가장 짧게 나타났다. 아기를 캐리어 없이 가슴에 안고 걸을 때 $(126.17 \pm 10.29 \mathrm{~cm} / \mathrm{s})$ 가장 빨리 걸었으며, 아기 캐 리어의 경우 힙시트 캐리어 $(123.51 \pm 11.34 \mathrm{~cm} / \mathrm{s})$, 아기띠 $(121.60 \pm 9.60 \mathrm{~cm} / \mathrm{s})$, 힙시트 $(118.80 \pm 9.27 \mathrm{~cm} / \mathrm{s})$ 착용 순으로 천천히 걷는 것으로 나타났다.

지면반력변인 아기띠를 제외(조건 A)하고 아기 캐리어 없이 아기 안기, 힙시트 캐리어, 힙시트를 착용하고 아기 를 안고 보행 시 왼발의 첫 번째와 두 번째 최대 지면반력 값 사이에 차이가 있는 것으로 나타났다(Table 5). 아기 캐 리어 조건에 상관없이 왼발과 오른발의 첫 번째 최대 지 면반력값에서 큰 차이가 나타났다.

\section{논의}

본 연구는 엄마 피험자가 아기 캐리어 착용 후 보행 시 체중분배, 자세 정렬과 보행 변수의 변화가 분석되었다. 엄마 피험자가 아기 캐리어를 사용하지 않고 아기를 가 슴에 안고 걸었을 때 엉덩이관절의 움직임이 작은 반면
무릎과 발목관절의 움직임은 크게 나타났다. 이는 엄마 가 아기를 떨어뜨리기 않기 위해 엄마의 팔로 아기를 감 싸고 엄마의 허리, 가슴과 어깨 쪽으로 아기를 가깝게 안 았기에 엉덩이관절의 소극적인 움직임이 나타난 것으로 생각된다.

아기 캐리어 중 힙시트를 사용하여 아기를 안고 걸었 을 때 엉덩이관절의 움직임이 작게 나타났는데, 이는 힙 시트가 아기의 엉덩이를 받치는 시트로만 이루어져 있고 엄마의 허리를 감싸는 스트랩이 다른 아기 캐리어에 비 해 넓기에 보행 시 엉덩이관절의 움직임에 영향을 준 것 으로 추측된다. 또한 본 실험에 참여한 엄마 피험자 모두 힙시트를 사용해 본 경험이 없었던 것도 영향을 주었을 것이다.

본 연구에서 엄마 피험자가 아기를 가슴에 안고 보행 시 아기 캐리어를 사용했을 때 보다 몸통의 굴곡 각도가 작게 나타났다. 아기 캐리어 없이 아기를 안을 때 아기의 몸을 지지해 줄 수 있는 등받이 또는 엉덩받이가 없기에 엄마는 아기 캐리어를 사용했을 때 보다 몸통을 세우고 걷는 것으로 보인다. 아기 캐리어를 사용하여 보행 시 아 기는 자연스럽 게 등받이 또는 엉덩받이 쪽으로 기대기에 아기 몸무게만큼의 부하가 진행방향과 수직방향으로 향 하게 된다. 따라서 엄마의 몸통 움직임은 보행의 진행방 향으로 더 많이 향하게 된다. 아기 캐리어를 이용 한 보행 시 엄마 몸통의 과도한 굴곡은 오랜 시간 아기 캐리어 사 용 시 자세의 균형을 깨뜨릴 수 있으며 낙상의 위험을 증 가시키고, 자세의 흔들림이 증가할수록 신체의 균형을 악 화시키는데 기여하였다[12].

분석 된 보행 변인들 중 힙시트 착용 후 보행 시 보폭과 활보장의 크기가 가장 짧게 나타났으며, 보행속도도 가 장 느리게 나타났다. 힙시트는 아기의 엉덩이 크기의 작 은 스티로폼이 천으로 감싸져 있고 두꺼운 허리 벨트가 연결된 형태이다. 힙시트는 실험에 사용된 다른 아기 캐 리어들과 달리 아기를 힙시트에 앉히고, 엄마가 팔로 아 이의 몸을 감싸 안아야지만 엄마의 움직임이 가능하다. 힙시트 보행은 다른 아기 캐리어 또는 아기 캐리어를 사 용하지 않은 채 아기를 가슴에 안고 걷는 보행 동작들 보 다 보폭과 활보장이 작고 보행 속도도 느린 것으로 나타 났는데 이 결과는 눈 여겨 볼만하다. 실험에 참여한 엄마 피험자들의 힙시트 사용 경험의 부재로 인한 것인지, 아 기의 몸을 감싸는 부분과 엄마의 어깨를 지지하는 어깨 스트랩이 없는 힙시트의 구조로 인해 아기를 보호하기 위 
Table 4. Gait variables (Mean \pm SD)

\begin{tabular}{ccccc}
\hline Gait variables & Normal & $\begin{array}{c}\text { Baby } \\
\text { carrier }\end{array}$ & $\begin{array}{c}\text { Hipseat } \\
\text { carrier }\end{array}$ & Hipseat \\
\hline Stance phase(\%) & $63.78 \pm 1.22$ & $63.75 \pm 1.43$ & $63.75 \pm 1.67$ & $63.92 \pm 1.31$ \\
Step length(cm) & $66.83 \pm 2.58$ & $66.06 \pm 3.37$ & $66.68 \pm 4.68$ & $64.10 \pm 3.83$ \\
Stride length(cm) & $132.42 \pm 5.44$ & $130.66 \pm 5.85$ & $131.64 \pm 8.16$ & $127.03 \pm 7.77$ \\
Gait velocity(cm/s) & $126.17 \pm 10.29$ & $121.60 \pm 9.60$ & $123.51 \pm 11.34$ & $118.80 \pm 9.27$ \\
\hline
\end{tabular}

Table 5. Vertical Ground Reaction Force (Mean \pm SD)

\begin{tabular}{cccccc}
\hline \multicolumn{2}{c}{$\begin{array}{c}\text { Vertical Ground Reaction Force } \\
\text { variables }\end{array}$} & Normal & $\begin{array}{c}\text { Baby } \\
\text { carrier }\end{array}$ & $\begin{array}{c}\text { Hipseat } \\
\text { carrier }\end{array}$ & Hipseat \\
\hline \multirow{2}{*}{ First Peak(\%BW) } & Left & $1.33 \pm 0.11$ & $1.32 \pm 0.11$ & $1.32 \pm 0.11$ & $1.32 \pm 0.08$ \\
& Right & $1.39 \pm 0.10$ & $1.36 \pm 0.10$ & $1.40 \pm 0.11$ & $1.35 \pm 0.07$ \\
Second Peak(\%BW) & Left & $1.31 \pm 0.07$ & $1.32 \pm 0.07$ & $1.29 \pm 0.05$ & $1.29 \pm 0.05$ \\
& Right & $1.33 \pm 0.07$ & $1.34 \pm 0.07$ & $1.35 \pm 0.07$ & $1.30 \pm 0.05$ \\
\hline
\end{tabular}

Note.

The left foot is stepped forward to the first forceplate and the right foot is stepped forward to the second forceplate.

한 소극적인 보행으로 나타난 것인지에 대한 추후 연구 가 필요하다.

아기 캐리어 없이 아기를 가슴에 안고 걷는 동작 시 엄 마들의 보행 속도가 아기 캐리어를 사용했을 때 보다 현 저히 빠르게 나타났다. 실험 전 엄마 피험자들의 아기 캐 리어 사용 용도와 빈도를 조사 한 결과, 엄마 피험자들은 아기를 재우거나 가까운 곳으로 외출 할 때도 아기 캐리 어를 자주 사용하는 것으로 나타났다. 따라서 엄마 피험 자들이 $10 \mathrm{~kg}$ 이상 몸무게의 아기를 아기 캐리어 없이 가슴 에 안고 약 $8 \mathrm{~m}$ 의 보행주로를 5 회 이상 걸은 것은 쉽지 만 은 안은 과제였다고 생각된다. 또한 아기 캐리어 없이 아 기를 가슴에 안고 걷는 동작은 아기의 몸무게(부하)가 일 정하게 분산되지 않는데, 이는 피로, 불편함, 아기의 상태 에 영향을 주어 엄마 피험자는 빠른 발걸음으로 성큼성큼 걸어 과제를 끝내고자 한 것으로 조심스럽 게 추측해본다.

본 연구에서 아기띠를 제외한 모든 보행 동작에서 두 번째 수직지면반력값이 첫 번째 수직지면반력값 보다 작게 나타났다. 두 번째 수직지면반력값은 보행 시 진 행방향으로 나아가는 추진력으로 해석되는데, Birrell \& Haslam [13]은, 감소된 추진력은 피험자의 몸 앞에 위치한
부하로 인해 지면을 힘차게 밀어내기 위해 줄어든 것으로 해석하였다. 왼발과 오른발의 첫 번째 수직지면반력값 또 한 차이를 보였는데, 발뒤꿈치로 지면을 내디딜 때 앞쪽 에 안은 아기로 인해 균형감이 다소 깨져 뒤뚱거리는 형 태의 걸음걸이를 구사하는 것으로 보인다.

아기를 양육하는 엄마들은 엄마 몸무게의 약 $1 / 5$ 을 차 지하는 아기를 안을 때 아기 캐리어나 팔을 이용한다. 본 연구의 결과 장시간의 아기 캐리어 사용은 엄마 몸통의 과도한 굴곡을 일으킬 수 있으며, 아기의 몸무게가 증가 하면 엄마는 더욱 더 뒤뚱거리는 보행을 할 것으로 예상 된다. 또한 아기 캐리어를 사용하지 않고 아기를 가슴에 팔로 안고 걷는 동작은 부하의 고른 분배가 불가능하기에 오랜 시간 동안 움직임을 유지하는 것이 어려울 것이다. 따라서 아기 캐리어는 편리함, 아기와 엄마와의 교감, 돌 봄을 위해 필요한 도구이지만 엄마의 신체 정렬과 보행에 큰 영향을 주기에 사용 시 주의가 필요하다.

본 연구는 다양한 아기 캐리어 사용 시 엄마 보행의 특 징을 분석하고자 하였으나, 소수의 피험자만이 본 연구 에 참여하여 통계적으로 유의한 결과를 도출할 수 없었 다. 따라서 추후연구로 모집단을 대표할 수 있는 다수의 
엄마 피험자가 참여하여 다양한 아기 캐리어 착용 후 행 하는 보행의 특성이 어떻게 나타나는지를 분석하는 것이 필요하다. 또한 아기를 안고 하는 보행(아기 캐리어 착용 유 또는 무)의 비교뿐 만 아니라 엄마 피험자의 일반 보행 동작과 비교.분석하여 부하로 인한 보행동작의 변화를 살 펴보는 것도 의미 있는 연구가 될 것이다.

\section{결론}

엄마가 가슴에 아기를 안고 걷는 동작은 아기 캐리어 사용 시의 보행과는 다른 양상을 보였다. 아기 캐리어 중 힙시트를 사용하여 걸을 때 엉덩이관절, 보폭, 활보장, 보 행 속도에서 차이가 나타났다. 아기 캐리어는 아기의 성 장과 돌봄에 필요한 도구임에도 불구하고 디자인, 제품 의 상태와 사용 등의 적정성, 과학적 근거 가 부족하다. 따 라서 엄마의 아기 캐리어 착용 시 행하는 다양한 움직임 에 대한 과학적 분석과 자료가 요구된다.

\section{Acknowledgements}

이 논문은 2015년 정부(교육부)의 재원으로 한국연구재단 의 지원을 받아 수행된 연구임(NRF-2015S1A5B5A07042111)

\section{Conflicts of Interest}

The authors declare no conflict of interest.

\section{References}

1. Foti T, Davids JR, Bagley A. A biomechanical analysis of gait during pregnancy. J Bone Joint Surg Am. 2000; 82(5):625-632.

2. Gilleard W, Crosbie J, Smith R. Effect of pregnancy on trunk range of motion when sitting and standing. Acta Obstet Gynecol Scand. 2002; 81(11):1011-1020.

3. Turgut F, Turgut M, Cetinsahin M. A prospective study of persistent back pain after pregnancy. Eur J Obstet Gynecol Reprod Biol. 1998; 80(1):45-48.

4. Wang SM, Dezinno P, Maranets I, Berman MR,
Caldwell-Andrews AA, Kain ZN. Low back pain during pregnancy: prevalence, risk factors, and out-comes. Obstet Gynecol. 2004; 104(1):65-70.

5. Norén L, Ostgaard, S, Johansson G, Ostgaard HC. Lumbar back and posterior pelvic pain during pregnancy: a 3-year follow-up. Eur Spine J. 2002; 11(3): 267-271.

6. Padua L, Caliandro P, Aprile I, Pazzaglia C, Padua R, Calistri A, Tonali P. Back pain in pregnancy: 1-year follow-up of untreated cases. Eur Spine J. 2005; 14(2): 151-154.

7. Lee SY, Chang JS, Lee MH. The Effects of Plantar Foot Pressure and EMG Activation of Neck, Lumbar and Low by Using Carrier during Walking. J Kor Soci Sport Biomech. 2009; 19(2):237-244.

8. Anderson AM, Meador KA, McClure LR, Makrozahopoulos D, Brooks DJ, Mirka GA. A biomechanical analysis of anterior load carriage. Ergonomics. 2007; 50(12):2104-2117.

9. Kim K, Yun, KH. The Effects of Body Posture by Using Baby Carrier in Different Ways. J Kor Soci Phy Med. 2013; 8(2):193-200.

10. Yuk GC, Park RJ, Lee HY, Lee MH, Lee JH, Kuk JS, Jang JS. The Effects of Baby Carrier and Sling in Muscle Activation of Trunk, Low Extremity and Foot Pressure. J Kor Soci Phy Med. 2010; 5(2):223-231.

11. Chang JS, Lee SY, Lee MH, Kim JH, Kim CY. The Effects of EMG activation of Neck, Lumbar and Low Limb by Using Baby Carrier with Arms during Walking. J Kor Soci Phy Med. 2010; 5(3):323-330.

12. Frisbee SJ, Hennes H. "Adult-worn child carriers: a potential risk for injury. Inj. Pre. 2000; 6:56-58.

13. Birrell SA, Haslam RA. The influence of rifle carriage on the kinetics of human gait. Ergonomics. 2008; 51: 816-826. 